\title{
The Prevalence of Diabetic Impotence
}

\author{
D. K. McCulloch, I. W. Campbell, F. C. Wu, R. J. Prescott, and B. F. Clarke \\ Diabetic and Dietetic Department, Royal Infirmary, and Medical Computing and Statistics Unit, Edinburgh University, \\ Edinburgh, Scotland
}

Summary. In a survey of 541 diabetic males, aged 20-59 years, $190(35 \%)$ had erectile impotence. Using linear logistic regression models for analysis the five most significant associations with impotence were age $(p<0.001)$, treatment with either insulin or oral hypoglycaemic agents $(\mathrm{p}<0.001)$, retinopathy $(\mathrm{p}<0.001)$, symptomatic peripheral neuropathy $(\mathrm{p}<0.001)$ and symptomatic autonomic neuropathy $(\mathrm{p}<0.005)$. The greatest correlations were found in patients with severe microangiopathy, as demonstrated by proliferative retinopathy and symptomatic autonomic neuropathy. In addition the duration of diabetes and the presence of ischaemic heart disease, nephropathy and poor diabetic control may also be associated with diabetic impotence. It is concluded that diabetic impotence is still a common problem and may have a multifactorial aetiology.

Key words: Diabetic impotence, prevalence, aetiological factors.

The increased frequency of impotence in the diabetic male has long been recognised [7]. Despite improvement in the treatment of diabetes since the early insulin era there has been no decrease in recent reports of the frequency of diabetic impotence $[7,10$, 14]. Thus the prevalence of impotence with increasing age in diabetic men aged between $20-60$ years is still approximately $18-71 \%$ [19] and considerably greater than $0.1-18.4 \%$ for the corresponding normal male population [13].

There has been no previous extensive survey of the prevalence of diabetic impotence in the United Kingdom. The aim of the present study was therefore to ascertain the prevalence in males attending a large
U. K. diabetic clinic. An assessment was also made of possible contributing factors involved in the aetiology of diabetic impotence.

\section{Materials and Methods}

During a nine month period 563 males attending the Diabetic Out-Patient Department were interviewed. A total of 132 clinics were covered and at each clinic every male aged between $20-59$ years was included. After three months an initial non-randomised group of 319 men (Group 1) had been interviewed. At this time it was decided to interview a random group of approximately 100 men to exclude the possibility of bias in the original group. The total clinic male population aged $20-59$ years was 887 and from the remaining 568, a random sample of 101 men (Group 2) was drawn who were subsequently interviewed over a six month period. Over this latter period a second non-random group of 121 men (Group 3) who were attending the clinic and not included in the random sample were also interviewed.

The total number of men included for study was thus 541 , representing $61 \%$ of the male clinic population aged between $20-59$ years. A further 22 who were unable to give satisfactory interviews were omitted: in the two non-random groups (Groups 1 and 3) 9 were mentally defective, 2 had cerebrovascular accidents with dysphasia and 2 were unable to speak English; in the random group (Group 2) 5 had recently left the area, 1 was hospitalised elsewhere, 2 were mentally defective and 1 had a cerebrovascular accident.

A detailed questionnaire was completed and included the patient's age, weight and standard weight (Metropolitan Life Insurance Company Tables, 1959), age at onset of diabetes and marital status. Diabetic treatment was recorded as diet alone, oral hypoglycaemic agents or insulin. Enquiry was made of other drug therapy, angina pectoris, previous myocardial infarction or cardiac failure, intermittent claudication, thyroid dysfunction, previous sympathectomy or other abnormality that might predispose to organic impotence such as neurological disease or previous injury. A note was taken of the average weekly quantity of alcohol consumed by each patient.

All patients had a retinal examination at least yearly with both pupils dilated and retinopathy status was recorded as none, background, exudative (or maculopathy) or proliferative, many of the latter having had or were awaiting photocoagulation treatment. The presence of nephropathy was indicated from several urinal- 
yses over the previous 12 months using "Albustix" and the proteinuria recorded as none $(0)$, intermittent $(0 /+)$, moderate $(++)$ or heavy $(+++)$.

Careful enquiry was made of symptoms suggestive of peripheral neuropathy (numbness, parasthesiae, burning pains and limb weakness).

These individual features were graded as "mild/moderate" or "severe". Objectively, those with mild/moderate complaints usually had documented in their case records absent ankle jerks, absent vibration sense at the ankle, diminished sensation in the feet and/or muscle wasting. Those with severe symptoms generally had more extensive sensory loss in the lower limbs, absent knee jerks and often had evidence of recent or old neuropathic ulceration. The criteria for the presence of symptomatic peripheral neuropathy were one or more severe or two or more mild/moderate symptoms along with objective evidence (as outlined above) that these symptoms were due to neuropathy.

Enquiry was also made of symptoms of autonomic neuropathy (postural hypotension, intermittent diarrhoea especially nocturnally, epigastric fullness, bladder dysfunction, diminished sweating in the legs, gustatory sweating and hypoglycaemic unawareness). The criteria for the presence of symptomatic autonomic neuropathy were two or more severe or three or more mild $/ \mathrm{mod}-$

Table 1. Relationship of age to impotence in diabetic males

\begin{tabular}{lccc}
\hline $\begin{array}{l}\text { Age range } \\
\text { (years) }\end{array}$ & $\begin{array}{l}\text { Total no. } \\
\text { diabetics }\end{array}$ & $\begin{array}{l}\text { No. } \\
\text { impotent }\end{array}$ & $\begin{array}{l}\% \\
\text { impotent }\end{array}$ \\
\hline $20-24$ & 53 & 3 & 5.7 \\
$25-29$ & 35 & 5 & 14.3 \\
$30-34$ & 44 & 7 & 15.9 \\
$35-39$ & 43 & 13 & 30.2 \\
$40-44$ & 52 & 15 & 28.8 \\
$45-49$ & 91 & 33 & 36.3 \\
$50-54$ & 99 & 49 & 49.5 \\
$55-59$ & 124 & 65 & 52.4 \\
\hline Total & 541 & 190 & $35.1 \%$ \\
\hline
\end{tabular}

erate features. All such patients had well defined objective evidence of autonomic neuropathy from previous studies $[8,2]$. Diabetic control was assessed by taking the average of the last six. $2 \mathrm{~h}$ post prandial glucose estimations at previous clinic visits or all the $2 \mathrm{~h}$ post prandial glucose values excluding the initial reading if the patient had only been attending for a short time. Three groups of diabetic control were arbitrarily designated:

Good - mean blood glucose level less than $9 \mathrm{mmol} / \mathrm{l}$;

Fair - 9.1-13.9 mmol/1;

$\mathrm{Bad}-14.0 \mathrm{mmol} / \mathrm{l}$ or greater.

The patient was also asked if he was able to obtain a normal penile erection and impotence was regarded as present if there had been partial or complete failure to obtain an erection for at least six months. The duration of impotence was recorded in months. If the patient was potent at the time of interview, enquiry was made if transient impotence had ever been present in the past, e.g. during anxiety or poor control. Such patients were entered in the study as being potent. Any decrease in libido was noted and enquiry was made for features suggestive of a psychological cause for the impotence [4].

The information was recorded on a questionnaire form, coded and transferred to punch cards. Using the Edinburgh Regional Computing Centre's facilities the computer package SPSS was used for the production of the tables. In the tabulations which follow three age groups were chosen to give adequate numbers in each group - 20-34 years, 35-49 years, 50-59 years. Patient Groups 1, 2 and 3 were compared using Chi-squared tests or a one-way analysis or variance dependent upon whether the variable concerned was qualitative or quantitative.

Investigation of the association of various clinical features with impotence involved the use of linear logistic models which were fitted using a second computer package, Genstat. The use of such models is well described by Cox [5]. They allow the probability of impotence to be related to a set of clinical variables simultaneously. In this way the interrelationship of the variables can be taken into account and the relative importance of the variables in producing impotence can be assessed. The method has considerable similarities to methods of multiple regression, which are well described by Armitage [1].

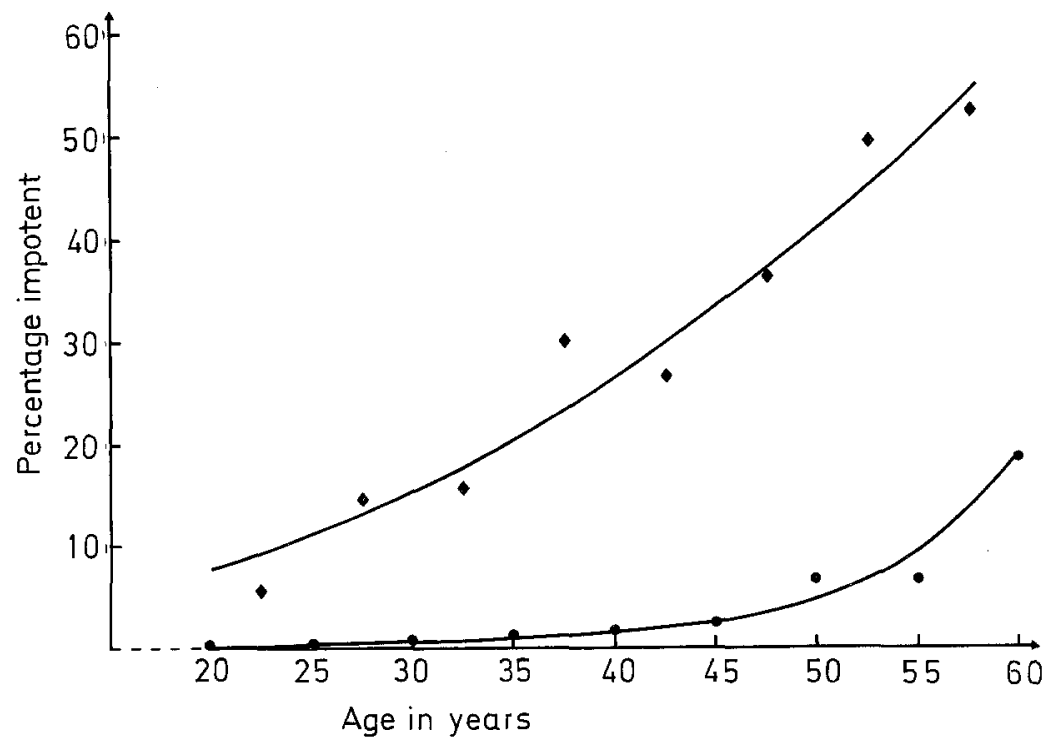

Fig. 1. Relationship of impotence to age in diabetic and normal male subjects. The normal male data are derived from Kinsey et al. [13].

$\longrightarrow$ Normal, $\longrightarrow$ Diabetics 
Table 2. Relationship of duration of diabetes to impotence in insulin dependent and insulin independent males within three age groups

\begin{tabular}{|c|c|c|c|c|c|c|}
\hline \multirow[b]{2}{*}{ Duration (years) } & \multicolumn{3}{|c|}{$\begin{array}{l}\text { Insulin dependent diabetics } \\
\text { age (years) }\end{array}$} & \multicolumn{3}{|c|}{$\begin{array}{l}\text { Insulin independent diabetics } \\
\text { age (years) }\end{array}$} \\
\hline & $20-34$ & $35-49$ & $50-59$ & $20-34$ & $35-49$ & $50-59$ \\
\hline $0-4$ & $5 \%(2 / 40)$ & $18 \%(2 / 11)$ & $33 \%(3 / 9)$ & $0 / 6$ & $16 \%(9 / 58)$ & $35 \%(26 / 75)$ \\
\hline $5-14$ & $16 \%(10 / 61)$ & $38 \%(15 / 40)$ & $50 \%(13 / 26)$ & $0 / 1$ & $53 \%(9 / 17)$ & $50 \%(28 / 56)$ \\
\hline $15-29$ & $13 \%(3 / 24)$ & $44 \%(20 / 45)$ & $79 \%(26 / 33)$ & - & $0 / 2$ & $63 \%(5 / 8)$ \\
\hline $30+$ & - & $46 \%(6 / 13)$ & $81 \%(13 / 16)$ & - & - & - \\
\hline
\end{tabular}

\section{Results}

Comparison of the non-randomised groups (1 and 3) and the randomised group (2) were made. The differences between the groups are outlined below. There were few significant differences and they were such that the amalgamation of the grouped data would give valid results on diabetic impotence. The ages of the three groups were comparable with mean \pm S. E. M. of group 1, 2 and 3 being $43.4 \pm 0.6,46.1 \pm$ 1.1 and $43.7 \pm 1.1$ respectively. The overall prevalence of impotence was $35 \%, 39 \%$ and $31 \%$ respectively in the three groups. The only variables demonstrating significant differences between the groups at the $5 \%$ level were retinopathy with prevalences of $34 \%, 22 \%$ and $26 \%$ respectively and symptomatic peripheral neuropathy with prevalences of $23 \%$, $13 \%$ and $14 \%$ in the three groups. All subsequent analyses were therefore performed with the combined data from all three groups, treating this as if it were a random sample from the clinic population.

Of the 541 men interviewed, $190(35 \%)$ were impotent (Table 1). The increasing prevalence of impotence with age is shown in the figure and over the age range studied this relationship can be described adequately by a logistic curve.

The effect of duration of diabetes on the prevalence of impotence within the three age groups is shown in Table 2 . There was an increasing prevalence of impotence with increasing duration of diabetes in all age groups but no difference in prevalence was seen between the insulin dependent and insulin independent groups.

Two hundred and eighty $(80 \%)$ of the potent and $173(91 \%)$ of the impotent subjects were married. Libido was diminished in $29(8.3 \%)$ of the potent diabetics and in $53(28 \%)$ of the impotent diabetics. In the latter none had features suggestive of psychogenic impotence and it may be that the diminished libido was secondary to the impotence. Transient impotence had occurred in 24 of the potent subjects, 8 during poor control, 4 during anxiety and 12 at other times such as at diagnosis of diabetes ( 3
Table 3. Relationship of diabetic treatment, retinopathy, peripheral and autonomic neuropathy to impotence within three age groups

\begin{tabular}{|c|c|c|c|}
\hline \multirow[b]{2}{*}{ Variable } & \multicolumn{3}{|l|}{ Age (years) } \\
\hline & $20-34$ & $35-49$ & $50-59$ \\
\hline \multicolumn{4}{|l|}{ Treatment } \\
\hline Insulin & $12 \%(15 / 125)$ & $39 \%(43 / 109)$ & $65 \%(55 / 84)$ \\
\hline Oral agents ${ }^{a}$ & $0 \%(0 / 3)$ & $35 \%(13 / 37)$ & $56 \%(43 / 77)$ \\
\hline Diet & $0 \%(0 / 4)$ & $13 \%(5 / 40)$ & $26 \%(16 / 62)$ \\
\hline \multicolumn{4}{|l|}{ Retinopathy } \\
\hline None & $5 \%(5 / 96)$ & $24 \%(29 / 120)$ & $39 \%(63 / 162)$ \\
\hline Background & $10 \%(2 / 20)$ & $34 \%(12 / 35)$ & $74 \%(26 / 35)$ \\
\hline Exudative & $0 \%(0 / 4)$ & $46 \%(6 / 13)$ & $94 \%(16 / 17)$ \\
\hline Proliferative & $67 \%(8 / 12)$ & $78 \%(14 / 18)$ & $100 \%(9 / 9)$ \\
\hline \multicolumn{4}{|c|}{ Peripheral neuropathy } \\
\hline Absent & $7 \%(8 / 116)$ & $27 \%(44 / 151)$ & $44 \%(75 / 169)$ \\
\hline Present & $44 \%(7 / 16)$ & $57 \%(20 / 35)$ & $72 \%(39 / 54)$ \\
\hline \multicolumn{4}{|c|}{ Autonomic neuropathy } \\
\hline Absent & $9 \%(11 / 127)$ & $30 \%(54 / 179)$ & $49 \%(104 / 213)$ \\
\hline Present & $80 \%(4 / 5)$ & $100 \%(7 / 7)$ & $100 \%(10 / 10)$ \\
\hline
\end{tabular}

${ }^{a}$ Within the group of patients on oral hypoglycaemic agents there was no difference in impotence in each age group in those taking sulphonylureas or biguanides (metformin)

subjects), following excessive alcohol (2 subjects) and during intercurrent unrelated illnesses such as myocardial infarction.

Using the linear logistic model five variables showed a significant association with impotence: age $(p<0.001)$, treatment of diabetes with insulin or oral hypoglycaemic agent but not diet alone $(\mathrm{p}<$ $0.001)$, retinopathy $(\mathrm{p}<0.001)$, symptomatic peripheral neuropathy $(\mathrm{p}<0.001)$ and symptomatic autonomic neuropathy $(p<0.005)$. A summary of the effects of these latter four variables is shown in Table 3 within the three age groups. Impotence was seen in all patients aged 50 years or more with proliferative retinopathy and in those aged 35 or more with autonomic neuropathy.

The presence of ischaemic heart disease, nephropathy and poor diabetic control may also be 
Table 4. Relationship of nephropathy, control of diabetes and ischaemic heart disease to impotence within three age groups

\begin{tabular}{|c|c|c|c|}
\hline \multirow[b]{2}{*}{ Variable } & \multicolumn{3}{|l|}{ Age (years) } \\
\hline & $20-34$ & $35-49$ & $50-59$ \\
\hline \multicolumn{4}{|l|}{ Nephropathy ${ }^{a}$} \\
\hline None $(0)$ & $7 \%(8 / 109)$ & $28 \%(43 / 155)$ & $47 \%(93 / 196)$ \\
\hline $\begin{array}{l}\text { Intermittent } \\
(0 /+)\end{array}$ & $18 \%(2 / 11)$ & $44 \%(8 / 18)$ & $68 \%(13 / 19)$ \\
\hline $\begin{array}{l}\text { Moderate } \\
(++)\end{array}$ & $40 \%(4 / 10)$ & $63 \%(5 / 8)$ & $100 \%(4 / 4)$ \\
\hline $\begin{array}{l}\text { Heavy } \\
(+++)\end{array}$ & $50 \%(1 / 2)$ & $100 \%(5 / 5)$ & $100 \%(4 / 4)$ \\
\hline \multicolumn{4}{|l|}{ Control $^{a}$} \\
\hline Good & $7 \%(2 / 29)$ & $21 \%(13 / 61)$ & $34 \%(25 / 74)$ \\
\hline Fair & $9 \%(5 / 53)$ & $28 \%(21 / 75)$ & $54 \%(53 / 98)$ \\
\hline Poor & $16 \%(8 / 50)$ & $54 \%(27 / 50)$ & $71 \%(36 / 51)$ \\
\hline \multicolumn{4}{|c|}{ Ischaemic heart disease } \\
\hline Absent & $11 \%(15 / 132)$ & $33 \%(54 / 166)$ & $48 \%(83 / 174)$ \\
\hline Present & - & $35 \%(7 / 20)$ & $63 \%(31 / 49)$ \\
\hline
\end{tabular}

a Nephropathy and control are defined in the patients and methods section

Table 5. A review of studies outlining the prevalence of impotence in diabetic men

\begin{tabular}{lll}
\hline Reference & $\begin{array}{l}\text { Number } \\
\text { of diabetics }\end{array}$ & $\%$ impotent \\
\hline 21 & 198 & 55 \\
23 & 314 & 51 \\
17 & 436 & 52 \\
20 & 350 & 75 \\
19 & 146 & 43 \\
7 & 200 & 59 \\
10 & 299 & 40 \\
14 & 175 & 49 \\
\hline Present study & 541 & 35 \\
\hline
\end{tabular}

associated with diabetic impotence (Table 4). However, these latter variables are closely associated with the other risk factors and so statistical significance is only achieved at the $10 \%$ level. Likewise, duration of diabetes was not found to have a statistically significant association with the prevalence of impotence when analysed using the linear logistic regression model. This occurs despite its obvious aetiological importance, because its effect on the model is indirect. Duration of diabetes is associated with an increasing prevalence of many other aetiological factors such as microangiopathy and neuropathy and so its individual importance is not considered to be significant in the context of the analysis using the linear logistic model.

\section{Discussion}

In our study the prevalence of impotence $(35 \%)$ is the lowest so far reported compared with other recent surveys from USA, Europe and South America (Table 5). We have studied the largest number of patients, aged 20-59 years, but otherwise unselected as regards treatment, duration or complications. In addition the study was conducted over a nine month period to include less frequent attenders at the clinic. Our method of selection thus ruled out some of the bias in selection present in previous studies. Although impotence as in non-diabetics increases with age, in our survey $76(24 \%)$ of those less than 50 years were impotent.

In the survey impotence was defined as the inability to initiate and sustain a satisfactory penile erection. Penile erection occurs as a reflex mediated by the parasympathetic nerve fibres from the spinal cord segments sacral 2-4 (nervierigentes). It is generally assumed that diabetic impotence is due solely to autonomic neuropathy affecting these nerves. This is mainly based on indirect evidence that impotence is associated with both anatomical [9] and physiological abnormalities [6] of the bladder in some of these diabetics. There has been one unconfirmed study showing alterations in the autonomic nerve fibres in the corpora cavernosa in impotent diabetics [11], again suggesting that a neurological lesion could cause the impotence.

However, in our previous studies of autonomic neuropathy we have shown that impotence can frequently occur alone without any of the other symptom-complexes of autonomic neuropathy and in such patients cardiovascular reflexes such as the Valsalva manoeuvre and the blood pressure response to sustained handgrip are normal [8] as is the plasma renin response to standing [3] as well as the preservation of normal testicular sensation [2]. There is now agreement that there is no obvious endocrine abnormality causing diabetic impotence and normal gonadotrophin levels [10], normal testosterone concentrations [14] and a normal gonadotrophin response to LH-RH stimulation [25] have been reported. It has become clear to those dealing with diabetic impotence that in some cases there would appear to be many disease processes such as psychogenic, neurological and vascular disorders involved in the aetiology of impotence, an idea suggested in 1950 by Simpson [24]. Although psychogenic factors are the commonest cause of non-diabetic impotence, we have been impressed by how infrequently any of the diabetic males had features to suggest psychogenic cause [4].

That impotence in normal males [13] and in diabetics [21] increases with age is well recognised. 
The significant association of impotence with diabetics on oral agents and insulin rather than diet alone differs from previous studies where impotence occurred equally in patients on all forms of therapy $[23,17]$. Our results suggest that impotence may be associated with an increased tendency to microangiopathy. The strong correlation with the presence and severity of retinopathy has not been shown by others. In the smaller study of Rubin and Babbott [21] retinopathy occurred with equal frequency in both potent and impotent diabetics. The association of impotence with neuropathic symptoms is not unexpected. There are many previous studies to show that impotence is found in a high percentage of patients with peripheral neuropathy $[22,16]$ and with autonomic neuropathy $[7,9]$.

An association with ischaemic heart disease was found at the $10 \%$ level but no significant association was found with the presence of intermittent claudication. A prerequisite for normal erection is an adequate blood supply to the genital region as seen by the occurrence of impotence in the Leriche syndrome [15]. Rubin and Babbott [21] found an equal incidence of vascular disorders in their potent and impotent diabetics. In an unconfirmed angiographic study in impotent diabetics Fournier and Huguet [12] have claimed an absence of blood supply to the corpora cavernosa of the penis. However, more extensive investigations of penile blood supply have not been carried out.

There are many variables therefore in the aetiology of diabetic impotence. Although it is possible to identify the predominant cause in some patients, detailed investigations of subgroups of impotent patients will be necessary to clarify the problem further.

Acknowledgement. We are most grateful for the help of Mrs. Sarah Dickson in the Diabetic Department, Royal Infirmary of Edinburgh and Wilma Hepburn in the Medical Computing and Statistics Unit, for their help in the preparation of this paper.

\section{References}

1. Armitage P (1971) Multiple regression and multivariate analysis. In: Statistical methods in medical research. Blackwell, Oxford, p 302-348

2. Campbell IW, Ewing DJ, Clarke BF, Duncan LJP (1974) Testicular pain sensation in diabetic autonomic neuropathy. $\mathrm{Br}$ Med J II: 638-639

3. Campbell IW, Ewing D J, Anderton J L, Thompson J H, Horn D B, Clarke B F (1976) Plasma renin activity in diabetic autonomic neuropathy. Eur J Clin Invest 6: 381-385

4. Cooper AJ (1972) Diagnosis and management of "endocrine impotence". Br Med J II: 34-36

5. Cox D R (1970) The linear logistic model. In: Analysis of binary data. Methuen, London, p 14-29
6. Ellenberg M, Weber H (1967) The incipient asymptomatic diabetic bladder. Diabetes 16: 331-335

7. Ellenberg M (1971) Impotence in diabetes: the neurologic factor. Ann Intern Med 75: 213-219

8. Ewing D J, Campbell I W, Burt A A, Clarke B F (1973) Vascular reflexes in diabetic autonomic neuropathy. Lancet II: 1354-1356

9. Faerman I, Maler M, Jadzinsky M, Alvarez E, Fox D, Zilbervarg J, Cibeira J B, Colinas R (1971) Asymptomatic neurogenic bladder in juvenile diabetics. Diabetologia 7: 168-172

10. Faerman I, Vilar O, Rivarola MA, Rosner J M, Jadzinsky MN, Fox D, Perez Loret A, Bernstein-Hahn L, Saraceni D (1972) Impotence and diabetes. Studies of androgenic function in diabetic impotent males. Diabetes 21: 23-30

11. Faerman I, Glocer L, Fox D, Jadzinsky MN, Rapaport M (1974) Impotence and diabetes. Histological studies of the autonomic nervous fibres of the corpora cavernosa in impotent diabetic males. Diabetes 23: 971-976

12. Fournier AM, Huguet JF (1968) Vascularisation du bulbe caverneux. Aspect normal et pathologique (cas particulier du diabète). J Radiol Electr Med Nucl 49: 515-518

13. Kinsey A C, Pomeroy WB, Martin CE (1948) Age and sexual outlet. In: Sexual behaviour in the human male. Saunders, Philadelphia, p 218-262

14. Kolodny RC, Kahn CB, Goldstein H H, Barnett D M (1974) Sexual dysfunction in diabetic men. Diabetes 23: 306-309

15. Leriche $\mathrm{R}$ (1940) De la résection du carrefour aortico-iliaque avec double sympathectomie lombaire pour thrombose artéritique de l'aorte; le syndrome de l'obliteration terminoaortique par artérite. Presse Med 48: 601-604

16. Martin MM (1953) Involvement of autonomic nerve-fibres in diabetic neuropathy. Lancet I: 560-565

17. Montenero P, Donatone E (1962) Diabète et activité sexuelle chez l'homme. Diabete 10: 327-335

18. Neubauer M, Demisch K, Schöffling K, Wiegelmann W, Salbach HG (1971) Andrologische Untersuchungen, Testosteronspiegel im Plasma und Choriongonadotropin - Belastungen bei Diabetikern mit Potenzstörungen. Verh Dtsch Ges Inn Med 77: 1060-1063

19. Neubauer M, Schöffling K (1977) Sexualstörungen bei diabetischen Männern. In: Oberdisse K (ed) Handbuch der inneren Medizin, 7/2B: Diabetes Mellitus. Springer, Berlin Heidelberg New York, p 465-505

20. Prikhozhan, VM (1967) Impotence in diabetes mellitus. Probl Endokrinol (Mosk) 13: 37-41

21. Rubin A, Babbott D (1958) Impotence and diabetes mellitus. J A M A 168: 498-500

22. Rundles R W (1945) Diabetic neuropathy; general review with report of 125 cases. Medicine (Baltimore) 24: 111-160

23. Schöffling K (1960) Störungen der Keimdrüsenfunktion bei männlichen Zuckerkranken. Beitr. Sexualforsch 19: 1-83

24. Simpson SL (1950) Impotence. Br Med J I: 692-697

25. Wright A D, London D R, Holder G, Williams JW, Rudd B T (1976) Luteinizing release hormone tests in impotent diabetic males. Diabetes 25: 975-977

Received: January 23, 1979, and in revised form: October 5, 1979

Dr. D. K. McCulloch

Diabetic and Dietetic Department

Royal Infirmary

Edinburgh EH3 9YW

Scotland 